de se esperar uma análise mais rica de temas como a manipulação da gestualidade, do vocabulário e do vestuário. Mesmo que nos filmes analisados esses elementos sejam de fato exacerbados e conduzam à construção de personagens homossexuais estereotipados, não se pode esquecer que o uso do escracho e do deboche também é uma das formas que as minorias detêm de se fazerem ver e de criticarem uma ordem vigente para elas indesejada. Tal uso talvez também pudesse ser lido, sem embargo da existência de preconceito e discriminação, como uma das poucas alternativas disponíveis aos diretores para que pudessem dar voz a figuras homossexuais. Isso não é examinado pelo autor. Uma aproximação com os estudos de Mikhail Bakthin, por exemplo, teria levado o autor a olhar para essas questões de um patamar diferenciado. Tivesse servido-se desses estudos, teria ainda examinado o "poder que o cinema exerce sobre o pensamento das pessoas" (p. 36) de forma mais circular e elástica, lembrando que as audiências reconstroem significados e atribuem sentidos diferentes aos discursos e imagens que lhes são apresentados.

Mas talvez o grande problema do livro esteja situado na forma como é criticada a representação do homossexual no cinema. Ao opor-se à exposição de tipos afeminados e marginais, o autor não visualiza que esses não são somente criações de diretores e autores nem produtos de um olhar preconceituoso da nossa sociedade. São figuras reais que, com suas crises e histórias dramáticas, habitam a cultura homossexual brasileira e que, portanto, também têm direito a serem apresentadas e representadas. Até porque, ontem e hoje, aqui e alhures, são justamente os tipos mais 'desviantes' que normalmente assumem a linha de frente nos enfrentamentos mais duros pelos direitos gays. Nesse domínio a argumentação de Moreno aproxima-se bastante de um discurso que, ao buscar desconstruir uma imagem negativa fixada, sugere um novo 'modelo' de homossexual (despido de trejeitos, profissional, 'sexualmente responsável', etc.) ajustado à organização de gênero que hoje conhecemos. ${ }^{3} \mathrm{~A}$ nosso ver talvez fosse uma causa mais justa advogar por espaço para que todos - gays efeminados e masculinos, desviantes e adaptados aos padrões sociais predominantes - fossem igualmente representados.

1 BOURDIEU, Pierre. Sobre a televisão. Rio de Janeiro: Jorge Zahar, 1997. p. 28.

${ }^{2}$ Sobre tal circulação ver: GREEN, James. Além do caranaval: a homossexualidade masculina no Brasil do século XX. São Paulo: UNESP, 2000; e MOTT, Luiz. Homossexuais da Bahia: dicionário biográfico. Salvador: Editora Grupo Gay da Bahia, 1999.

${ }^{3}$ Para uma análise, a partir da experiência americana, das implicações políticas e culturais - em especial a exclusão - contidas nos esforços de certos setores do movimento gay em recriar a figura do "bom homossexual", ver GÓIS, J. B. H. "A conservadorização do discurso anti-AIDS nos Estados Unidos". Revista Serviço Social e Sociedade, n. 58, 1998.

JOÃO BÔSCO HORA GÓIS Universidade Federal Fluminense

\title{
Feministas interrogam os estudos de religião
}

\author{
Feminism and Religion, an \\ Introduction.
}

GROSS, Rita.

Boston, Beacon Press, 1996. 279 p.

A autora dessa obra é professora de Filosofia e Estudos Religiosos na Universidade de WisconsinEau Claire, nos Estados Unidos. O livro Feminism and Religion, an Introduction organiza-se em seis capítulos. É apresentado pela autora como um estudo "cross-cultural", característica inerente à disciplina Estudos de Religião, não se limitando às religiões ou às teologias cristãs e pós-cristãs, nem ao feminismo ocidental. Gross propõe-se a realizar, com essa obra, duas tarefas, que considera cruciais aos estudos de feminismo e religião: oferecer informações sobre os papéis religiosos das mulheres e identificar a perspectiva feminista em cada uma das religiões estudadas. Sua abordagem é, ao mesmo tempo, descritiva e normativa. A autora pretende mostrar o que acontece quando métodos feministas são aplicados aos dados de pesquisas sobre religiões 
e quando feministas criticam e reconstroem suas religiões a partir de valores feministas.

O capítulo primeiro tem caráter metodológico. Discute as relações entre conhecimento acadêmico e escolhas pessoais. Pode-se 'compreender' a posição religiosa de alguém, sem que isso implique adesão à mesma posição. Há uma distinção entre conhecer, compreender e crer. Se é irrelevante definir a verdade ou a falsidade das idéias religiosas, é impossível compreender a história humana ignorando crenças e práticas religiosas de um povo. Reconhecendo a dificuldade de se chegar a uma definição de religião suficientemente ampla para abarcar todas as religiões existentes, isto é, uma definição não etnocêntrica, a autora propõe como central a qualquer religião a 'visão de mundo' que ela propicia ao grupo de fiéis. Assim, independentemente de seu conteúdo, qualquer crença que funcione como critério significativo para decisões e ações, e qualquer comportamento cujo valor seja ilimitado para o/ a ator/a, são crenças e comportamentos religiosos.

O método mais adequado aos estudos de religião é o da empatia. Pressupõe, por um lado, certo afastamento em relação aos próprios valores e visão de mundo; por outro, uma aproximação da religião em estudo. Em outras palavras: trata-se de buscar entender por que os/as insiders sentem-se compelidos por determinadas visões e impelidos a certos comportamentos. Essa aproximação das religiões é radicalmente desabsolutizadora: uma vez que se compreenda o ponto de vista do outro, a própria crença não será mais proposta como a única verdadeira.

O feminismo, por sua vez, é apresentado como método acadêmico e como visão sociopolítica. Como método acadêmico, é crítico do androcentrismo. Propõe a inclusão de informações sobre as mulheres, em todas as disciplinas. O fundamento dessa proposição está em uma compreensão andrógina da humanidade: um modelo de humanidade bissexuada. Como visão social, o feminismo desenvolve uma crítica da cultura patriarcal, resultado de processo histórico, e não de necessidade inevitável, derivada de uma determinação biológica qualquer. Distingue-se dos estudos acadêmicos feministas, mas interligase também com eles, de alguma forma.

O segundo capítulo apresenta uma breve história do impacto do feminismo sobre as religiões e sobre os estudos das religiões. Embora já no século XIX as mulheres falem criticamente sobre as religiões, é nos anos 1960 que os estudos feministas passam a desafiar o Judaísmo e o Cristianismo primeiro, e todas as religiões, em seguida.

No século XIX predominam as teorias do matriarcado, baseadas em Bachofen e Engels. A idéia da superioridade espiritual das mulheres, própria da época, permitiu que muitas mulheres cristãs se tornassem missionárias, desenvolvendo intensa atividade religiosa. Surgem as primeiras controvérsias a respeito da ordenação feminina. Em certas seitas, há uma clara contestação dos papéis tradicionalmente atribuídos às mulheres. Além de ativas participantes, elas são fundadoras de alguns desses movimentos alternativos.

Em 1895, é publicada a primeira importante contribuição feminista para a interpretação do texto bíblico: The Woman's Bible, organizada por Cady Stanton.

Nos anos 60 e 70, já no século XX, além de criticarem o sexismo das religiões e criarem movimentos espiritualistas fora do Cristianismo e do Judaísmo, um número significativo de mulheres recebe título de doutoras em Religious Studies. $O$ desenvolvimento dos estudos de religião feministas expressa-se na produção de livros, na criação de espaços específicos em organizações internacionais de pesquisa e na edição de revistas especializadas. Surgem problemas relativos à diversidade de interpretações. Duas correntes se formam: uma delas propõe a transformação das religiões históricas, enquanto a outra, mais radical, rompe com as tradições religiosas históricas, por considerá-las intrinsecamente sexistas e irreformáveis. Os estudos da religião de caráter feminista atingem todas as religiões: ocidentais cristãs; não-cristãs asiáticas e indígenas.

O capítulo terceiro trata dos desafios colocados pelas feministas aos estudos da religião. A proposta metodológica de Gross é a de aplicar um olhar andrógino à leitura das fontes androcêntricas existentes. Esse olhar supõe a inclusão de dados sobre a realidade religiosa das mulheres e sobre as normas culturais referidas a elas, bem como sobre deusas e outras figuras mitológicas femininas. A inclusão de informação sobre a vida religiosa das mulheres não significa apenas um acréscimo ao que já se sabe sobre aquela religião, mas modifica, muitas vezes, o conhecimento que se tem de toda a religião. $O$ exemplo escolhido é o do tratamento das deusas 
no panteão hindu. Mas a autora chama a atenção para simplificações como as que consideram que a simples existência de deusas torna uma religião benéfica para as mulheres, ou de que toda divindade feminina é amorosa e maternal. Gross destaca a necessidade de o estudo comparado das religiões mundiais retirar o foco dos tradicionais conceitos de divindade ou dos critérios geográficos. Refere uma classificação recente que organiza as religiões em um contínuo que vai do domínio dos homens à inclusão de um poder feminino genuíno. Outros critérios de classificação levam em conta a orientação mais familiar ou social das religiões e suas conseqüências diferenciadas para homens e mulheres. A consideração da presença ou da ausência de deusas é outro critério classificatório possível.

Um ponto metodológico central para a autora é o estudo minucioso de material já coletado sobre as religiões, para daí levantar exemplos representativos da imensa variedade histórica da vida religiosa das mulheres. Surgem então correlações inesperadas, como a que indica que nem todas as sociedades estudadas, no caso da pesquisa referida pela autora, são dominadas pelos homens. Ou que a religião é sempre um fator importante, esteja ou não presente a dominação masculina. E a indicação de que quase sempre, em sociedades dominadas pelos homens, a divindade é definida exclusivamente em termos masculinos.

O capítulo quarto é dedicado à discussão metodológica e de conteúdo das teologias cristãs e pós-cristãs, bem como das interpretações feministas do Hinduísmo e do Budismo.

A pergunta "Sempre foi assim?" norteia o quinto capítulo. A autora defende o caráter histórico, portanto passível de superação, do patriarcado, isto é, do domínio social e religioso dos homens, o que não permite afirmar, porém, a existência anterior de um matriarcado. Apesar de criticar a hipótese pré-patriarcal como eurocêntrica e unilear, difícil de sustentar-se academicamente, conclui ser razoável afirmar, a partir dos poucos dados históricos existentes, que as mulheres eram menos dominadas antes do patriarcado e a sacralidade feminina era comumente venerada. Gross propõe uma explicação materialista para as origens do patriarcado e do domínio religioso dos homens. O declínio do poder público das mulheres e da adoração das divindades femininas é antes efeito do que causa da patriarcado. Mudanças tecnológicas e mudanças nos símbolos religiosos e nas normas sociais são intimamente ligadas. A autora explora em seguida as relações entre a emergência do monoteísmo e do patriarcado. Retoma as teses das origens do Cristianismo e estabelece uma comparação acurada com o Hinduísmo e o Budismo.

O capítulo final explora a figura de uma religião pós-patriarcal, levantando diferentes formas existentes contemporaneamente, tanto nas religiões ocidentais quanto nas orientais e indígenas.Observações críticas - A obra de Gross é um marco nos estudos feministas da religião. Tem o mérito de propor, com seriedade intelectual e rigor metodológico, questões relativas à análise das religiões levando em conta tanto as religiões ocidentais como as orientais. Nesse aspecto, a obra fica omissa por não tratar das religiões afroameríndias, o que chama a atenção, dada a afirmação reiterada da autora da necessidade metodológica de não se restringir os estudos às religióes ocidentais. O livro acaba dando a impressão de que as religiões não-ocidentais restringem-se ao Budismo, ao Islam e ao Hinduísmo.

Embora a obra não seja dirigida a iniciantes nos estudos das religiões, poderá ser lida com proveito por pesquisadores/as, assim como por estudantes desse campo. Vale lembrar que o livro tem especial interesse para mulheres e homens estudiosos do feminismo.

MARIA JOSÉ F. ROSADO NUNES

Pontifícia Universidade Católica de São Paulo 